\title{
MicroRNA-146a Induced by Hypoxia Promotes Chondrocyte Autophagy through Bcl-2
}

\author{
Fei Zhang ${ }^{a}$ Jing Wang ${ }^{b}$ Jianjun Chu ${ }^{c}$ Cheng Yang ${ }^{b}$ Hui Xiao ${ }^{b}$ Chenglong Zhao ${ }^{b}$ \\ Zhengwang Sun $^{\mathrm{b}}$ Xin Gao ${ }^{\mathrm{b}}$ Guanghui Chen ${ }^{\mathrm{b}}$ Zhitao Han ${ }^{\mathrm{b}}$ Weiwei Zou ${ }^{\mathrm{d}}$ \\ Tielong Liu ${ }^{\mathrm{b}}$
}

aThe Center Hospital of Ningbo Development Zone, Ningbo, 'bThe Spinal Tumor Center, Changzheng Hospital, Second Military Medical University, Shanghai, 'The Department of Orthopedic Spine Surgery, Binhu Hospital, Hefei, 'The Department of Medical Imaging, Changzheng Hospital, Second Military Medical University, Shanghai, China

\section{Key Words}

Osteoarthritis (OA) • Cartilage • miR-146a • HIF-1 $•$ Autophagy

\begin{abstract}
Background/Aims: There have been many studies on the etiology of osteoarthritis (OA) with regard to the function of inflammatory cytokines, the process of cartilage degradation, the function of miR-146a, hypoxia stimulation and autophagy in OA chondrocytes, but there have been no reports on the relationship between miR-146a and autophagy in cartilage, especially under hypoxia. This study aimed to confirm the relationship of miR-146a and autophagy in cartilage under hypoxia. Methods: Chondrocytes were treated by hypoxia gradients, and the main factors including HIF- $1 \alpha$, HIF- $2 \alpha$, miR-146a and $\mathrm{BCl}-2$ and autophagy markers ULK1 , ATG-5 were detected by quantitative PCR (Q-PCR) and western blotting. The autophagy marker LC-3 was detected by immunofluorescence. The reciprocal effects between miR-146a and $\mathrm{Bcl}-2$ were confirmed by several combinations of shRNAs and adenovirus-gene systems followed by Q-PCR and western blot detection. Results: Hypoxia maintained the chondrocytes phenotype and promoted autophagy and miR-146a expression via HIF-1 $\alpha$, but not HIF-2 $\alpha$, while miR-146a did not reversely affect HIF-1 $\alpha$. The autophagy induced by hypoxia through HIF-1 $\alpha$, miR-146a and Bcl-2. Simply, hypoxia induced HIF-1 $\alpha$, and HIF-1 $\alpha$ increased miR-146a, but miR-146a suppressed $\mathrm{BCl}-2$, an autophagy inhibitor. While $\mathrm{Bcl}-2$ affected neither HIF-1 $\alpha$ nor miR-146a. The absence of both HIF-1 $\alpha$ and miR-146a or Bcl-2 over-expression inhibited hypoxia-induced autophagy. Conclusion: $\mathrm{HIF}-1 \alpha, \mathrm{miR}-146 \mathrm{a}$ and $\mathrm{Bcl}-2$ play crucial roles during hypoxia-induced autophagy, Hypoxia, HIF-1 $\alpha$ and miR-146a promote chondrocytes autophagy via depressing $\mathrm{Bcl}-2$. We conclude that miR-146a may serve as a novel therapeutic target for protecting cartilage from degeneration in $\mathrm{OA}$.
\end{abstract}

F. Zhang, J. Wang and J. Chu contributed equally to this work.

Weiwei Zou and Tielong Liu

KARGER 125
Department of Orthopaedics, Shanghai Changzheng Hospital, 415, Fengyang Road, Shanghai, 200003 (China)

E-Mail czyylt|@163.com and E-Mail czyyzww@163.com 


\section{Cellular Physiology Cell Physiol Biochem 2015;37:1442-1453 \begin{tabular}{l|l|l}
\hline DOI: 10.1159/000438513 & (C) 2015 S. Karger AG, Basel
\end{tabular} \\ and Biochemistry $\frac{\text { Published online: October 23, } 2015}{\text { Zhang et al.: An Investigation Focused on miR-146a and Autophagy in Chondrocytes }}$ under Hypoxia}

\section{Introduction}

Osteoarthritis $(\mathrm{OA})$ is the most common chronic degenerative disorder of the joint and is a rheumatic disease that affects the majority of individuals over the age of 65 [1]. It is characterized by articular cartilage degeneration, limited intra-articular inflammation such as synovitis, calcification of the subchondral bone and changes in the peri-articular tissue. The etiology of OA is very complex and poorly elucidated. Its pathogenesis includes genetic factors, aging of the cartilage, changes in the cartilage matrix structure, obesity, trauma and mechanical factors $[2,3]$.

The disruption of cartilage homeostasis and the initiation of the catabolic pathway are the most important hallmarks of OA. Articular cartilage mainly exists in a low-oxygen environment due to the existence of an air-poof joint capsule, so chondrocytes are adapted to this hypoxic condition. It has been reported that hypoxia triggers essential positive signals for the chondrocytes phenotype and that hypoxia-inducible factor HIF- $1 \alpha$ plays a crucial role during this process. HIF-1 $\alpha$ is mainly localized in the early differentiation stage chondrocytes and is up-regulated in dedifferentiated chondrocytes. HIF- $1 \alpha$ shows a capacity for inducing chondrogenesis in the setting of cartilage engineering. HIF- $1 \alpha$ effectively induced the chondrocyte phenotype of human bone marrow cells without exogenous growth factors [4]. In the hypoxia growth plate, HIF-1 $\alpha$ maintains chondrocytes function as professional secretory cells by regulating collagen production [5]. HIF-1 $\alpha$ not only inhibits the expression of COL1A1, COL1A2 and COL3A1 [6] but also simultaneously induces the expression of SOX9, COL2A1 and aggrecan [7]. HIF-1 $\alpha$ inhibits cell proliferation [8] and is a survival factor for hypoxic chondrocytes [9]. HIF-1 $\alpha$ also plays an important role in extracellular matrix synthesis by maintaining anaerobic glycolysis [10]. It was also shown that HIF-1 $\alpha$ serves to regulate both apoptosis and autophagy by modulating the autophagic proteins and caspase-8 [11]. In addition, the HIF- $1 \alpha$-dependent AMPK activation and mTOR suppression are key factors for chondrocytes autophagy during the micro-environmental changes experienced by the chondrocytes [12].

Autophagy is defined as an ordered cell response to various types of stress, whereby macromolecules and cellular organelles are engulfed and recycled to sustain cellular metabolism [13]. Autophagy has been shown to be important for lifespan extension in various organisms, and the longevity pathways significantly regulate numerous autophagy related proteins [14]. The reported diseases in which autophagy has a preventative, ameliorative or even rescue function include infections, cancer, neurodegeneration, aging, and heart disease [15]. Autophagy also exists in normal adult articular cartilage to maintain cellular homeostasis. Therefore, autophagy proteins such as ATG-5 (autophagy-related gene 5), BECN1 (Beclin 1, autophagy-related), and MAP1LC3 (microtubule-associated protein 1 light chain 3) are expressed in the superficial zone of the articular cartilage, and few chondrocytes in the deep cartilage zone express MAP1LC3 [16]. Autophagy significantly decreases during the aging process in mouse and human knee articular cartilage, as shown by the down-regulation of BECN1, MAP1LC3 and ULK-1 (unc-51-like autophagy activating kinase 1), and this phenomenon is accompanied by increased apoptosis [17]. Noticeably, a time-dependent reduction in autophagy was reported in a rapidly progressing experimental mouse model of OA [16]. Furthermore, cell death was increased in both surgically and mechanically injured $\mathrm{OA}$, suggesting that autophagy may contribute to survival mechanisms [18]. Increased autophagy is believed reflect an adaptive stress response to the development of $\mathrm{OA}$, and moreover, the failure of autophagy may lead to further cartilage degeneration.

Autophagy is regulated by many factors through different signaling pathways, including HIF-1, AMPK, mTOR, PI3K [19], and Beclin 1 [20]. Epigenetic control of autophagy is also the subject of attention in many fields. Histone acetylation activation and negative feedback [21], DNA methylation [22], and microRNAs (miRs) [23] have been reported to participate in epigenetic regulation. Most of these epigenetic regulation mechanisms occur through the reported factors or pathways, such as HDAC through P53 [24], FoxO3 [25], and ATG7 [26]; DNA methylation through mTOR and ATG1 [27]; miR-30A through beclin-1 [28]; miR- 


\section{Cellular Physiology Cell Physiol Biochem 2015;37:1442-1453 \begin{tabular}{l|l} 
Dol: 10.1159/000438513 & $\begin{array}{l}\text { 2015 s. Karger AG, Basel } \\
\text { www.karger.com/cpb }\end{array}$ \\
\hline
\end{tabular} \\ Zhang et al.: An Investigation Focused on miR-146a and Autophagy in Chondrocytes under Hypoxia}

101 through RAB5A, ATG4D, and STMN1 [29]; and miR-503 through p53 [30]. In particular, research on the relationship between miRs and autophagy has wildly and rapidly expanded in a relatively short time (less than 20 years from the discovery and definition of miRs). More than 50 miRs have been found to regulate autophagy through various target genes, and these studies suggest a close relationship between miRs and autophagy.

A miR is a small non-coding RNA molecule (containing approximately 22 nucleotides) found in plants, animals, and some viruses, which functions in RNA silencing and the posttranscriptional regulation of gene expression [31]. The miRs have been shown in various research fields to have a crucial regulatory role [31-33], and unsurprisingly, several miRs are involved in hypoxia regulation [34]. HIF-1 $\alpha$, as a crucial molecule in the hypoxic microenvironment, is an important link between miRs and hypoxia. More interestingly, the effect between miRs and HIF- $1 \alpha$ is reciprocal: some miRs regulate HIF-1 $\alpha$ expression [34], while HIF- $1 \alpha$ affects the levels of other miRs [35].

Thus, there are complex relationships among hypoxia, HIF-1 $\alpha$, miRs, autophagy and OA, or simply a three-way relationship among HIF- $1 \alpha$, miRs, and autophagy, because the connections between hypoxia and HIF [36], autophagy and OA [37], HIF-1 $\alpha$ and OA [5] are quite clear, as shown by many studies. However, each two of the three factors, HIF- $1 \alpha$, miRs, and autophagy, may have reciprocal effect to each other.

In the OA and miRs research field, miR-146a has received much attention since 2008, but its function in OA pathology is still controversial. Two opposite conclusions exist about miR-146a in OA, and each has been supported by multiple studies. However, to the best of our knowledge, there have been no reports on miR-146a and autophagy in OA pathology, especially under hypoxic conditions. Considering the important functions of hypoxia and autophagy in $\mathrm{OA}$, the exploration of the position of miR-146a in the complex network is necessary to understand and confirm its function in OA pathology.

\section{Materials and Methods}

\section{Cell culture and oxygen deprivation}

Cartilage slices were harvested from the articular cartilage of C57BL/6J mouse hip and knee joints and then cut into small pieces. The pieces were subsequently washed with sterile phosphate-buffered saline (PBS, pH 7.4) and digested in trypsin-EDTA (0.25\% w/v; Invitrogen, Carlsbad, CA) for 10 min and collagenase type II $(0.02 \% \mathrm{w} / \mathrm{v}$; Sigma-Aldrich, St. Louis, MO) for $5 \mathrm{~h}$. The isolated cells were seeded into $10 \mathrm{~cm}$ dishes (Corning, Corning, NY) and cultured in 1:1 DMEM/F12 with 10\% fetal bovine serum (FBS), $50 \mathrm{U} / \mathrm{ml}$ penicillin, and $50 \mathrm{mg} / \mathrm{ml}$ streptomycin. For hypoxic conditions, cells were cultured in a modular incubator chamber (Billups-Rothenburg, Del Mar, CA) that had been flushed with a mixture of $\mathrm{O}_{2}, \mathrm{~N}_{2}$ (the ratio was depended by the deigned proposal separately) and $5 \% \mathrm{CO}_{2}$ for $24 \mathrm{~h}$. Hypoxic conditions within the chamber were monitored by the YSI model 55 dissolved oxygen meter (YSI Inc., Yellow Springs, $\mathrm{OH}$ ).

\section{Real-time quantitative PCR}

Total RNA was extracted from chondrocytes (each experiment contained three repeats per group) after the cells were homogenized and lysed by a high-speed homogenizer in TriPure reagent (Roche Applied Science, Mannheim, Germany). The concentration and purity of mRNA were detected using a Nano-Drop 2000 spectrophotometer (Thermo Fisher Scientific, MA, U.S.). Real-time PCR was performed after reverse transcription using a Roche LC 480 real-time PCR system with SYBR® Premix (TaKaRa, Inc., Dalian, China). Glyceraldehyde 3-phosphate dehydrogenase (GAPDH) was used as an internal control. Data were analyzed by the $\mathrm{Ct}(2-\Delta \Delta \mathrm{Ct})$ method and are expressed as the fold change compared with GAPDH. miR-146a expression was measured using TaqMan miRNA Assays (Applied Biosystems) according to the manufacturer's instructions using a 7300 Real-time PCR thermocycler (Azco Biotech) with respect to U6 RNA (internal control). The primer sequences are shown in Table 1. Each sample was analyzed in triplicate.

Western Blotting

Cells were lysed on ice for $30 \mathrm{~min}$ in lysis buffer containing $50 \mathrm{mM}$ Tris- $\mathrm{HCl}, \mathrm{pH}$ 7.4, $150 \mathrm{mM} \mathrm{NaCl}$, $1 \%$ Nonidet P-40, and $0.1 \%$ SDS supplemented with protease inhibitors $(10 \mathrm{~m} \mathrm{~g} / \mathrm{ml}$ leupeptin, $10 \mathrm{~m} \mathrm{~g} / \mathrm{ml}$ KARGER 


\section{Cellular Physiology Cell Physiol Biochem 2015;37:1442-1453 \begin{tabular}{c|c} 
Dol: 10.1159/000438513 & $\begin{array}{l}\text { 2015 s. Karger AG, Basel } \\
\text { www.karger.com/cpb }\end{array}$ \\
\hline
\end{tabular} \\ Zhang et al.: An Investigation Focused on miR-146a and Autophagy in Chondrocytes under Hypoxia}

Table 1. Real time Polymerase Chain Reaction primers for mouse-specific gene expression analysis. Abbreviations: F, forward primer; $\mathrm{R}$, reverse primer

\begin{tabular}{|c|c|c|c|}
\hline Genes & Sequences of primers & GenBank accession number & Product sizes (bp) \\
\hline \multirow[t]{2}{*}{ GAPDH } & F: 5' AGGTCGGTGTGAACGGATTTG 3' & NM_008084 & 95 \\
\hline & R: 5' GGGGTCGTTGATGGCAACA 3' & & \\
\hline \multirow[t]{2}{*}{ HIF $1 \alpha$} & F: 5' GATGACGGCGACATGGTTTAC 3' & NM_010431 & 155 \\
\hline & R: 5' CTCACTGGGCCATTTCTGTGT 3' & & \\
\hline \multirow[t]{2}{*}{$\operatorname{HIF} 2 \alpha$} & F: 5' GAGGAAGGAGAAATCCCGTGA3' & NM_010137 & 161 \\
\hline & R: 5' TATGTGTCCGAAGGAAGCTGA3' & & \\
\hline \multirow[t]{2}{*}{ sox9 } & F: 5' AGTACCCGCATCTGCACAAC 3' & NM_011448 & 88 \\
\hline & R: 5' ACGAAGGGTCTCTTCTCGCT 3' & & \\
\hline \multirow[t]{2}{*}{ Col2a } & F: 5' GGGTCACAGAGGTTACCCAG 3' & NM_031163 & 85 \\
\hline & R: 5' ACCAGGGGAACCACTCTCAC 3' & & \\
\hline \multirow[t]{2}{*}{ MMP13 } & F: 5' TGTTTGCAGAGCACTACTTGAA 3' & NM_008607 & 132 \\
\hline & R: 5' CAGTCACCTCTAAGCCAAAGAAA 3' & & \\
\hline \multirow[t]{2}{*}{ ADAMTS5 } & F: 5' CCCAGGATAAAACCAGGCAG 3' & NM_011782 & 105 \\
\hline & R: 5' CGGCCAAGGGTTGTAAATGG 3' & & \\
\hline \multirow[t]{2}{*}{ ULK1 } & F: 5' AAGTTCGAGTTCTCTCGCAAG 3' & NM_009469 & 92 \\
\hline & R: 5' ACCTCCAGGTCGTGCTTCT 3' & & \\
\hline \multirow[t]{2}{*}{ ATG5 } & F: 5' TGTGCTTCGAGATGTGTGGTT 3' & NM_053069 & 126 \\
\hline & R: 5' ACCAACGTCAAATAGCTGACTC 3' & & \\
\hline \multirow[t]{2}{*}{$\mathrm{Bcl} 2$} & F: 5' GAGAGCGTCAACAGGGAGATG 3' & NM_177410 & 108 \\
\hline & R: 5' CCAGCCTCCGTTATCCTGGA 3' & & \\
\hline
\end{tabular}

pepstatin A, and $10 \mathrm{~m} \mathrm{~g} / \mathrm{ml}$ aprotinin). For western analysis, $15 \mu \mathrm{g}$ of sample was resolved by $12 \%$ SDSPAGE and electro-transferred onto nitrocellulose membranes (Whatman, Piscataway, NJ). The primary antibodies used were anti-ULK-1 (NBP2-24738, Novus Biologicals); anti-ATG-5 (NB110-53818, Novus Biologicals); anti-Bcl-2 (2876S, Cell Signaling Technology); LC3 (SAB1306673, Sigma-Aldrich); Beclin-1 (ab55878, Abcam) at a dilution of 1:500. To normalize protein loading, a GAPDH (2118L, Cell Signaling Technology) antibody was used at 1:2,000 dilution. HRP-conjugated secondary antibodies were used at a 1:2,000 dilution. The antigen-antibody complexes were visualized using an enhanced chemiluminescence detection system (Millipore, Billerica, MA) as recommended by the manufacturer.

\section{Construction of recombinant adenoviruses}

Recombinant adenoviruses expressing mouse HIF1 $\alpha$ and HIF2 $\alpha$, and short hairpin RNAs of HIF $1 \alpha$ and HIF $2 \alpha$ were prepared as described previously using the pAdEasyTM vector system (Qbiogene, USA). Briefly, HIF $1 \alpha$, HIF $2 \alpha$ and the LacZ sequence were cloned into pShuttle-CMV (Qbiogene, USA), and the short hairpin HIF1 $\alpha$ (shHIF1 $\alpha$ ) sequence 5'-GGAGGACGATGAACATCAAGT-3' and short hairpin HIF2 $\alpha$ (shHIF2 $\alpha$ ) 5'-GGGACTTACTCAGGTAGAACT-3' were each cloned into reconstituted pShuttle-U6 (Qbiogene, USA) and homologously recombined in bacteria BJ5183 with pAdEasy-1. The recombinant plasmids were propagated separately in HEK 293 cells.

Indirect immunofluorescence and confocal laser microscopy

Chondrocytes were grown on glass cover slips and cultured in normoxia or hypoxia situation as descripted above. The cells were then fixed with 4\% PBS-paraformaldehyde for 15 min and processed for immunofluorescence by LC-3 antibody (ab62720, Abcam, Cambridge, MA) at a dilution of 1:300 as previously described [38]. 


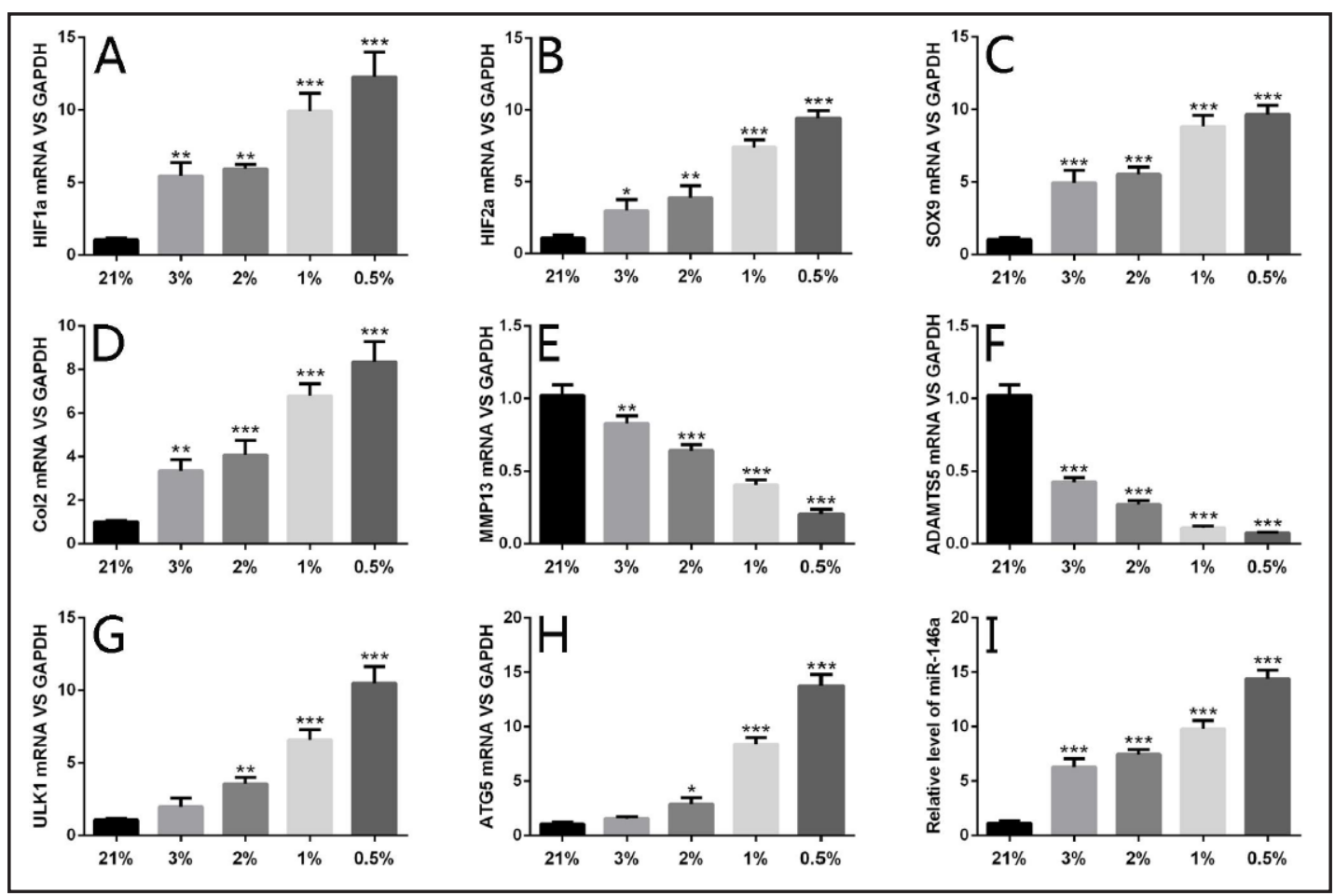

Fig. 1. Hypoxia maintained the chondrocyte phenotype and promoted autophagy and miR-146a expression. (A, B) Two crucial factors, HIF- $1 \alpha$ and HIF- $2 \alpha$, were promoted during hypoxia. (C, D) The cartilage phenotype was maintained in the hypoxic environment, as shown by SOX9 and Collagen II expression. (E, F) The expression of the principal cartilage proteases MMP-13 and ADAMTS-5 was significantly reduced by hypoxia. (G, H) Autophagy was activated in hypoxia, as shown by ULK-1 and ATG-5, two markers of autophagy. (I) Hypoxia significantly increased the miR-146a level. ${ }^{*}=\mathrm{P}<0.05 ;{ }^{* *}=\mathrm{P}<0.01$; ${ }^{* * *}=\mathrm{P}<0.001$ between two groups.

\section{Statistical analysis}

Results were expressed as mean \pm standard deviation. Statistical analysis was carried out using oneway ANOVA with Tukey's multiple comparisons test or two-way ANOVA with Sidak's multiple comparisons test. $\mathrm{P}$ values of less than $0.05,0.01$ or 0.001 was considered statistically significant, very significant or extremely significant respectively.

\section{Results}

Hypoxia maintained the chondrocytes phenotype and promoted autophagy and miR-146a expression

To explore the chondrocytes' reaction in hypoxic conditions, primary chondrocytes were cultured as monolayers under $21 \%$ oxygen tension or gradual hypoxia with $3 \%, 2 \%, 1 \%$ and $0.5 \% \mathrm{O}_{2}$. The crucial markers for hypoxia effect, HIF- $1 \alpha$ and HIF- $2 \alpha$, and crucial markers for chondrocytes, SOX9 and Col II, were all upregulated, as detected by Q-PCR (Fig. 1A, 1B, $1 \mathrm{C}$ and $1 \mathrm{D}$, respectively). However, two of the most common cartilage proteinases, MMP13 and ADAMTS-5, were significantly down-regulated (Fig. 1E, 1F). Meanwhile, autophagy was intensely promoted, as demonstrated by the expression of ULK-1 (most upstream autophagy inducer, Fig. 1G) and ATG-5 (an autophagy regulator Fig. 1H). Finally, miR-146a was significantly induced by the gradual hypoxia (Fig. 1I).

\section{Hypoxia induced miR-146a through HIF-1 $\alpha$}

To explore the mediator between hypoxia and miR-146a, we tested the effect of HIF$1 \alpha$ and HIF- $1 \alpha$ on miR-146a expression. Similar to the $0.5 \%$ hypoxia situation, additional 


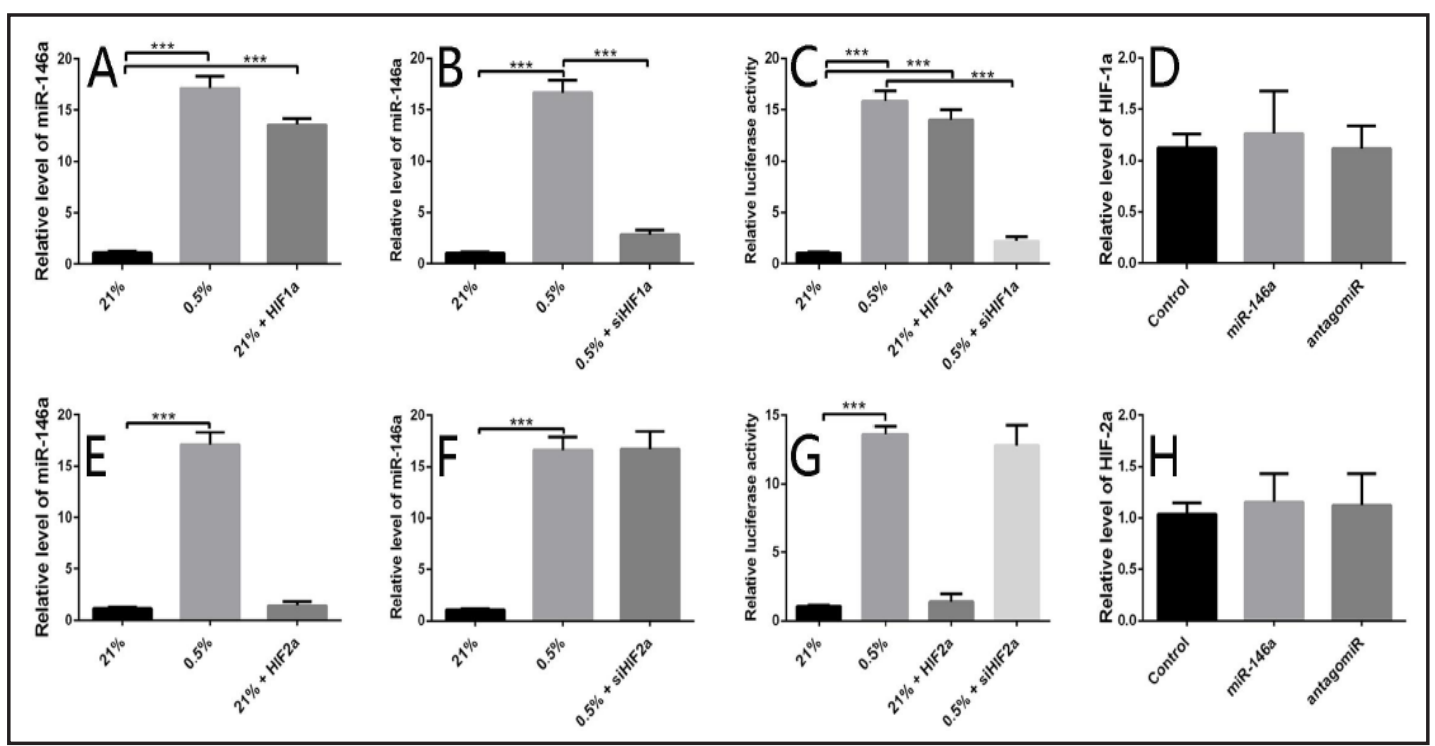

Fig. 2. Hypoxia induced miR-146a through HIF-1 $\alpha$. (A) HIF-1 $\alpha$ induced miR-146a in normoxic condition in a manner similar to that observed during hypoxia (0.5\% oxygen). (B) Hypoxia did not induce miR-146a in the absence of HIF-1 $\alpha$. (C) The luciferase results confirmed the induction of miR-146a by HIF-1 $\alpha$ and the crucial mediator role of HIF-1 $\alpha$ during hypoxia by inducing miR-146a. (D) miR-146a did not affect the HIF$1 \alpha$ level. (E-H) No reciprocal effect was found between HIF- $2 \alpha$ and miR-146a. ${ }^{*}=\mathrm{P}<0.05 ;{ }^{* *}=\mathrm{P}<0.01$; $* * *=\mathrm{P}<0.001$ between two groups.

HIF-1 $\alpha$ induced miR-146a in a normal $21 \%$ oxygen tension, as detected by Q-PCR (Fig. 2A). Notably, siHIF-1 $\alpha$ depressed $0.5 \%$ hypoxia induced miR-146a (Fig. 2B), and the luciferase result confirmed the trend discovered by Q-PCR (Fig. 2C). The potential effect of miR-146a on HIF- $1 \alpha$ was also detected considering that some miRs and HIF- $1 \alpha$ may have a reciprocal relationship with each other. Our results showed that miR-146a did not influence HIF- $1 \alpha$ significantly (Fig. 2D). The same methods were followed to study HIF-2 $\alpha$, but HIF- $2 \alpha$ did not influence miR-146a (Fig. 2E, 2F, 2G), and no reciprocal effect (Fig. 2H) was observed, thereby suggesting no connection between HIF- $2 \alpha$ and miR-146a. These results suggested that hypoxia up-regulates miR-146a through HIF-1 $\alpha$ instead of HIF-2 $\alpha$.

\section{Hypoxia promotes autophagy via HIF-1 $\alpha$ and miR-146a}

The autophagy markers ULK-1, ATG-5 and LC-3 were detected under the intervention of HIF- $1 \alpha$ and miR-146a. Similar to the $0.5 \%$ hypoxia situation, additional HIF- $1 \alpha$ and miR146 a induced ULK-1 and ATG-5 expression in a normal $21 \%$ oxygen tension, as detected by Q-PCR (Fig. 3A, 3B). Notably, siHIF- $1 \alpha$ and antagomiR reduced the $0.5 \%$ hypoxia-induced expression of ULK-1 and ATG-5 (Fig. 3C, 3D). Western blotting results of ULK-1, ATG-5, LC3-I and LC3-II (Fig. 3E) and confocal IF data (Fig. 3F) confirmed the trend discovered by Q-PCR (Fig. 3E). Together with the data shown in Fig. 2, we primarily speculated that hypoxia promoted autophagy by inducing HIF-1 $\alpha$ and miR-146a in the proper order.

\section{$B c l-2$, an autophagy mediator, is regulated by HIF-1 $\alpha$ and miR-146a}

According to a previous report, Bcl-2 is a possible target of miR-146a during autophagy [39], so we explored the function of Bcl-2 during hypoxia-induced autophagy. Bcl-2 expression was significantly reduced by $0.5 \%$ hypoxia, whereas both additional siHIF- $1 \alpha$ and antagomiR increased Bcl-2 expression, and similar to the $0.5 \%$ hypoxia situation, additional HIF- $1 \alpha$ and miR-146a reduced Bcl-2 expression in a normal 21\% oxygen tension as detected by Q-PCR (Fig. 4A). The Q-PCR result was confirmed by the western blotting data and Beclin-1 


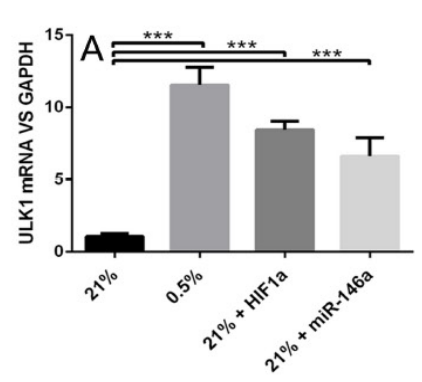

\section{$\mathrm{E}$}
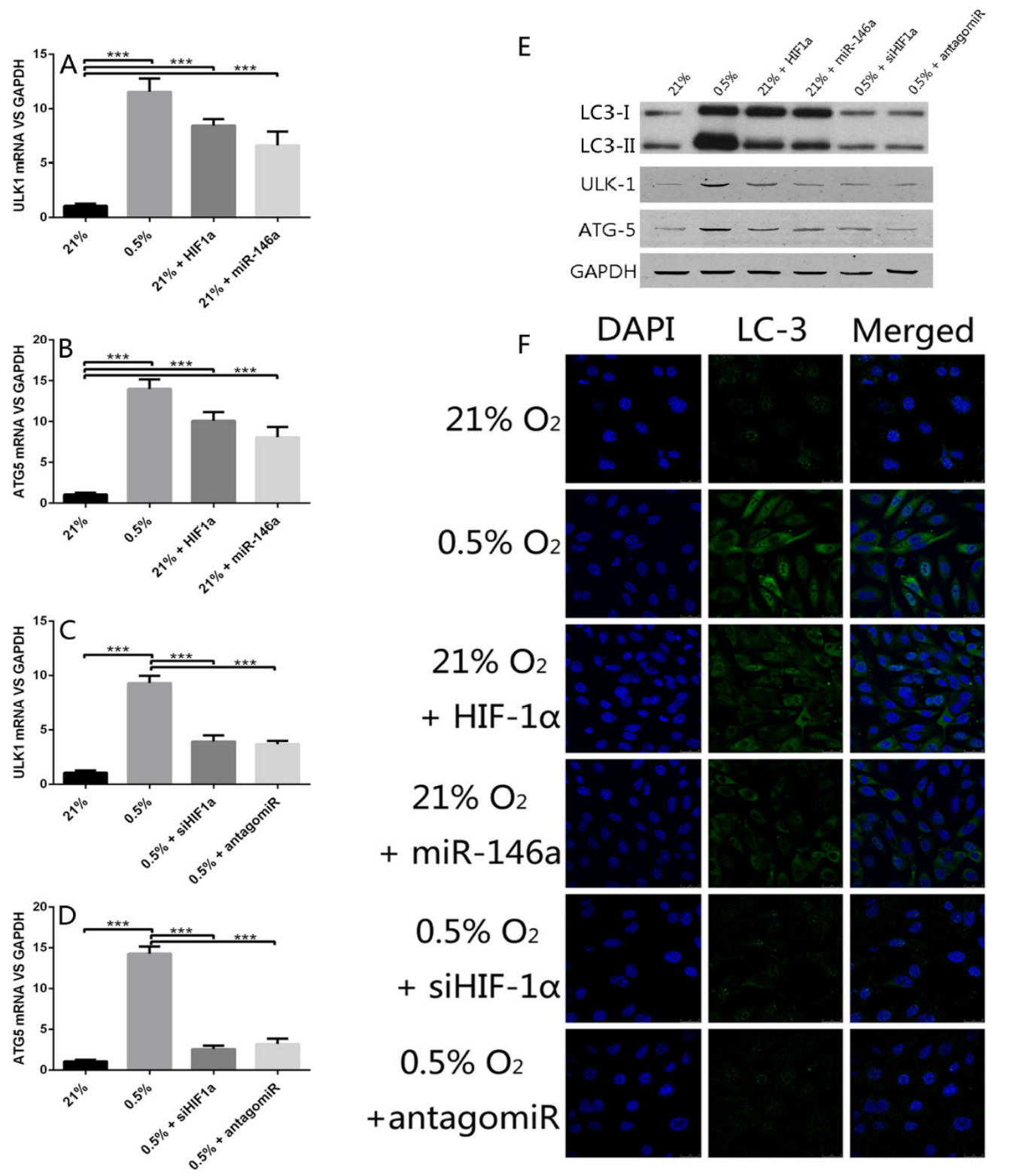

$$
\begin{gathered}
0.5 \% \mathrm{O}_{2} \\
+ \text { siHIF- } 1 \alpha \\
0.5 \% \mathrm{O}_{2} \\
+ \text { antagomiR }
\end{gathered}
$$

Fig. 3. Hypoxia promoted autophagy via HIF-1 $\alpha$ and miR-146a. (A, B) Both additional HIF-1 $\alpha$ and miR-146a led to autophagy in normoxic conditions. (C, D) The hypoxia-induced autophagy disappeared in the absence of HIF-1 $\alpha$ and miR-146a. (E, F) Western blotting results and confocal IF data each separately confirmed the autophagy trend discovered by $\mathrm{Q}-\mathrm{PCR}^{*}=\mathrm{P}<0.05$; $^{* *}=\mathrm{P}<0.01$; $^{* * *}=\mathrm{P}<0.001$ between two groups.

showed a reverse trend compare with Bcl-2(Fig. 4B). The respective counteractions of Bcl-2 in normoxia and hypoxia did not affect HIF-1 $\alpha$ and miR-146a.

\section{HIF-1 $\alpha$ and miR-146a regulated autophagy through Bcl-2}

Additional Bcl-2 inhibited autophagy in the 0.5\% hypoxia situation, whereas downregulation of Bcl-2 by siBcl-2 promoted autophagy in the normal $21 \%$ oxygen tension, as shown by the Q-PCR results for ULK-1 and ATG-5 and the confocal IF data for LC-3 (Fig. 5A-5C). Furthermore, additional Bcl-2 decreased the autophagy caused by HIF- $1 \alpha$ and miR146 a in normoxia (Fig. 5D-5F), and this phenomenon suggested that Bcl-2 is the downstream factor of miR-146a for autophagy regulation.

\section{KARGER}




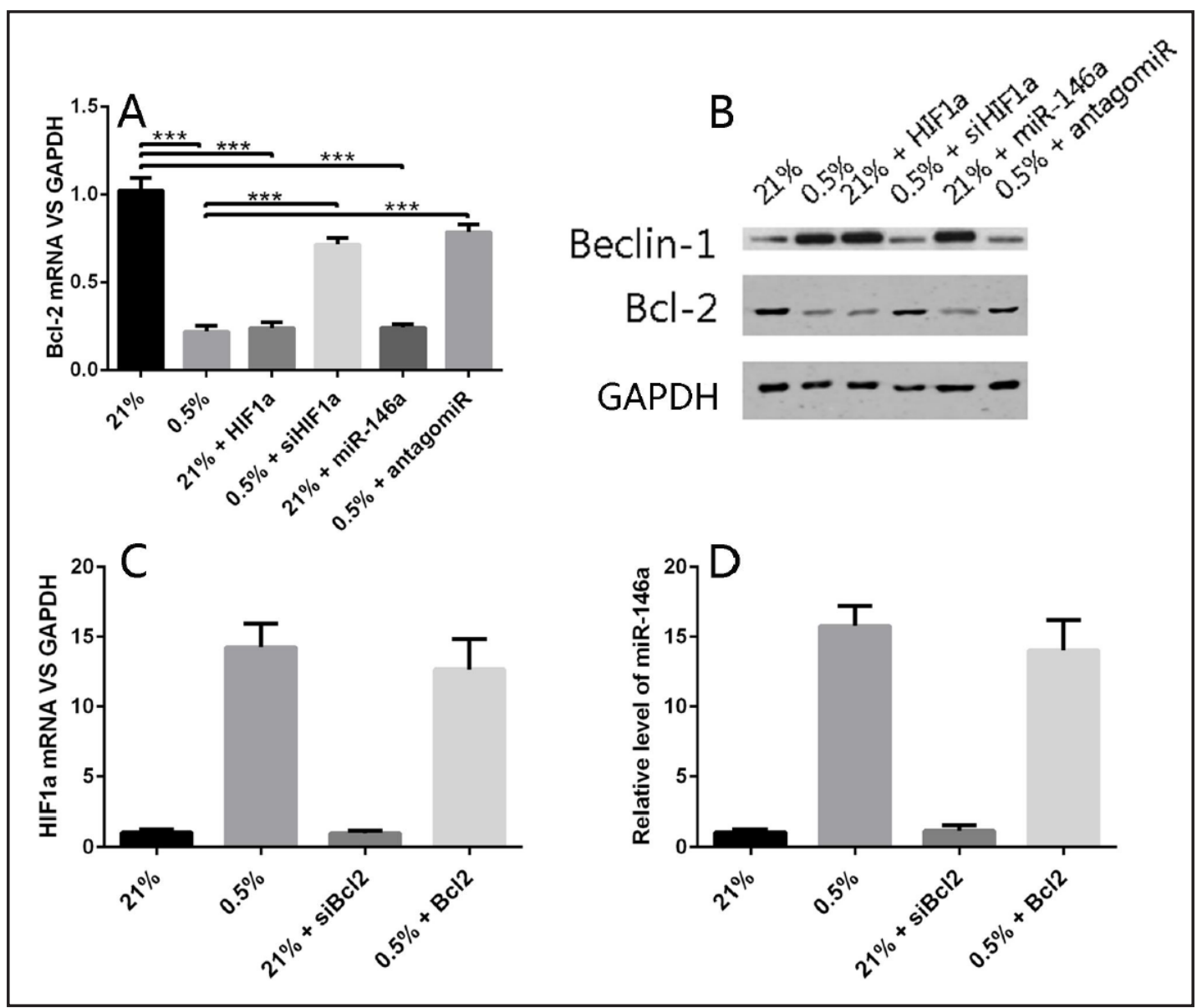

Fig. 4. Bcl-2 was regulated by HIF-1 $\alpha$ and miR-146a. (A, B) Bcl-2 expression was significantly reduced by hypoxia, whereas the absence of both HIF- $1 \alpha$ and miR-146a rescued Bcl-2 expression. Additional HIF- $1 \alpha$ and miR-146a in normoxic conditions decreased Bcl-2 expression significantly. Beclin-1 showed a reverse trend compare with Bcl-2. (C, D) Bcl-2 did not regulate HIF-1 $\alpha$ or miR-146a, as shown by the respective counteractions of Bcl-2 in normoxia and hypoxia. ${ }^{*}=\mathrm{P}<0.05$; $^{* *}=\mathrm{P}<0.01{ }^{* * *}=\mathrm{P}<0.001$ between two groups.

\section{Discussion}

The function of miR-146a in arthritis (both osteoarthritis and rheumatoid arthritis) pathology is still controversial despite having been studied for 6 years. Tomoyuki Nakasa et al. discovered that miR-146 is expressed in rheumatoid arthritis (RA) in 2008 and is induced by TNF $\alpha$ and IL-1 $\beta$ [40]. These results were confirmed by Kaleb Pauley et al. the same year. They reported between 1.8-fold and 2.6-fold increases in miR-146a, miR-155, miR-132 and miR-16 expression in RA and suggested a possible mechanism contributing to RA pathogenesis whereby miR-146a expression is increased but unable to properly function, leading to prolonged TNF $\alpha$ production in patients with RA [41]. However, the function of miR-146a in arthritis still needed further exploration. Jing Li et al. and Jin Lei et al. each demonstrated the function of miR-146a in OA, and their results are quite similar to each other. Briefly, IL-1 $\beta$ induced miR-146a over-expression in an experimental OA model, accompanied by up-regulation of VEGF and down-regulation of Smad4 in vivo. miR-146a may be involved in the pathogenesis of OA by promoting VEGF expression and impairing the TGF- $\beta$ signaling pathway through targeted inhibition of Smad4 in cartilage [42]. MiR146 a was over-expressed in the chondrocytes model of experimentally induced human mechanical injury, accompanied by the up-regulation of VEGF and the down-regulation of Smad4 in vitro. miR-146a is involved in human chondrocytes apoptosis in response to 


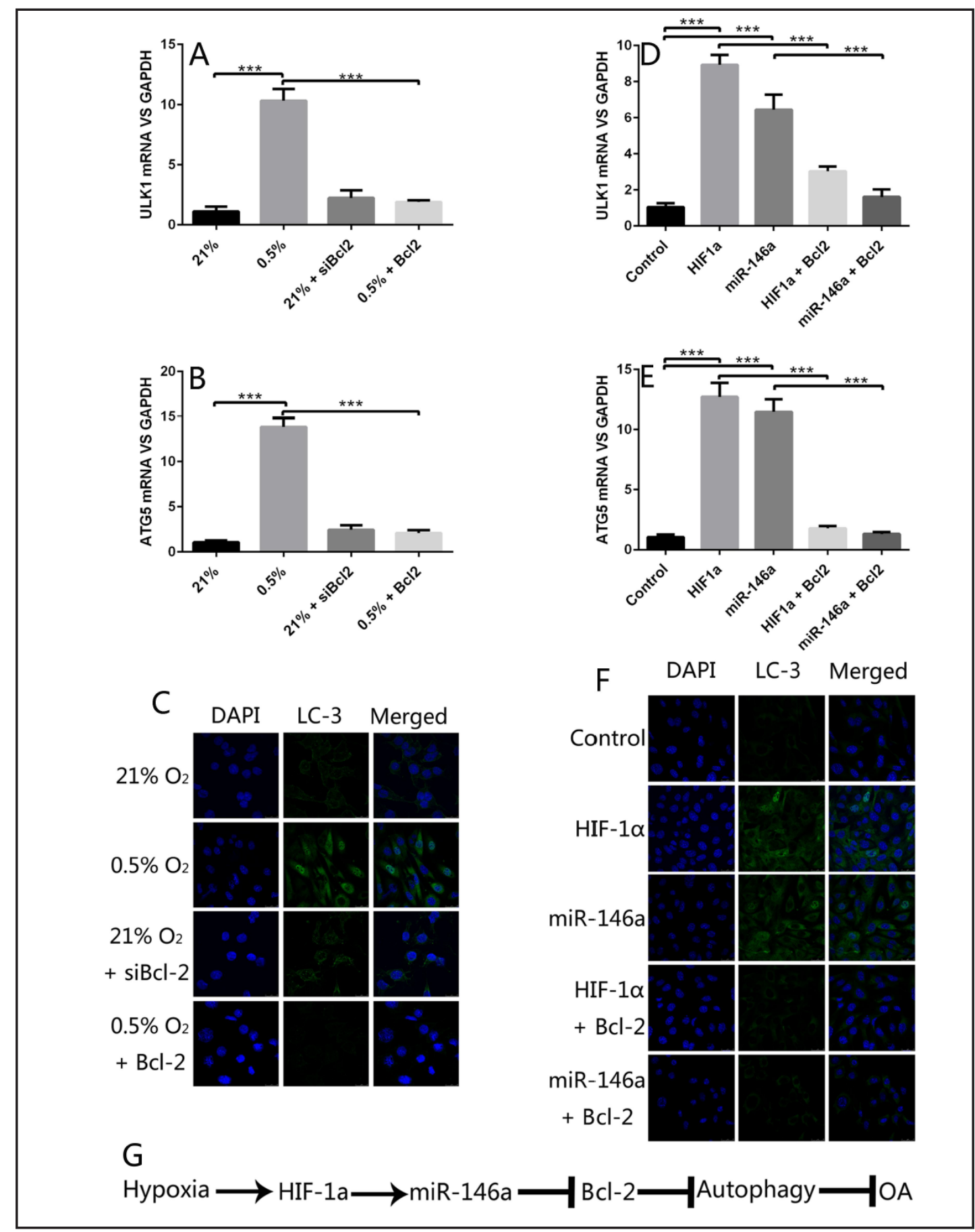

Fig. 5. HIF- $1 \alpha$ and miR-146a regulated autophagy through Bcl-2. (A-C) Additional Bcl-2 in hypoxic conditions significantly reduced the hypoxia-induced autophagy. (D-F) The autophagy induced by HIF-1 $\alpha$ and miR-146a in normoxia was significantly reduced by Bcl-2. (G) Brief flow chart of the ordered molecular mechanism discovered by this study. ${ }^{*}=\mathrm{P}<0.05$; $^{* *}=\mathrm{P}<0.01$; $^{* *}=\mathrm{P}<0.001$ between two groups.

mechanical injury and may contribute to the mechanical injury of chondrocytes as well as to OA pathogenesis by promoting VEGF expression and impairing the TGF- $\beta$ signaling pathway through inhibiting Smad4 in cartilage [43]. Both of these studies confirmed the participation of the VEGF, Smad4 and TGF- $\beta$ signaling pathway during the miR-146a-mediated OA pathology and discovered that Smad4 is the target of miR-146a in this process. However, 


\section{Cellular Physiology Cell Physiol Biochem 2015;37:1442-1453 \begin{tabular}{l|l} 
Dol: 10.1159/000438513 & $\begin{array}{l}\text { 2015 s. Karger AG, Basel } \\
\text { www.karger.com/cpb }\end{array}$ \\
\hline
\end{tabular} \\ Zhang et al.: An Investigation Focused on miR-146a and Autophagy in Chondrocytes under Hypoxia}

different functions of miR-146a were demonstrated in the immune system versus tumor research, which reported that miR-146a inhibits the expression of IRAK1 and TRAF6, impairs NF- $\kappa B$ activity and suppresses the expression of NF- $\kappa$ B target genes such as IL-1 $\beta$, IL-6, IL-8 and TNF- $\alpha$ [44]. Tomoyuki Nakasa et al. clearly reported that miR-146a expression inhibited osteoclastogenesis and that the administration of double-stranded miR-146a prevented joint destruction in arthritic mice. This result suggested a negative feedback between miR146a and inflammatory factors, considering that miR-146a was up-regulated in the RA pathology, and the administration of miR-146a may serve as a novel therapeutic target for bone destruction in RA [45]. The negative feedback of miR-146a with inflammatory factors was further confirmed in osteoarthritis fibroblast-like synoviocytes [46], osteoarthritis pain in knee joints [47], and intervertebral disc [48]. Apparently, there is still a great controversy on the role of miR-146a with two opposite conclusions, and one study reported a downregulation of miR-146 in OA cartilage, further mystifying the issue [49].

Many studies have been conducted on the role of miR-146a in OA pathology, but none have studied the molecule during hypoxia and autophagy considering the crucial effect of these two factors in the OA process. In this study, we have shown that miR-146a was induced during hypoxia by HIF-1 $\alpha$, and miR-146a promoted autophagy by decreasing Bcl-2 expression, an autophagy inhibitor. The crucial roles of each factor during hypoxiainduced autophagy were also confirmed separately. Therefore, according to our results, we can primarily speculate that the miR-146a can preserve cartilage from degeneration in $\mathrm{OA}$ considering the protective function of autophagy to the cartilage during OA pathology. This ordered process, shown in Fig. 5G, represents a potential molecular mechanism for the connection between hypoxia, miR-146a and autophagy and provides a possible therapeutic strategy for $\mathrm{OA}$ as the intra-articular injection of synthetic microRNAs as a novel therapeutic strategy.

This study is a primary study of the role of miR-146a in hypoxia and autophagy and of the detailed molecular mechanism among HIF-1 $\alpha$, miR-146a and Bcl-2, especially the direct target. The complicated network involving other factors such as TRAF6, mTOR, and others still needs further exploration, and we provide a new angle by which to investigate the role of miR-146a in cartilage degeneration during OA. This research area involving hypoxia, miRs and autophagy may provide a wealth of knowledge in the future.

\section{Acknowledgements}

This work was supported by the National Natural Science Foundation of China (Grant 81372874).

\section{Disclosure Statement}

The authors indicate no potential conflicts of interest.

\section{References}

1 Bijlsma JW, Berenbaum F, Lafeber FP: Osteoarthritis: an update with relevance for clinical practice. Lancet 2011;377:2115-2126.

2 Thysen S, Luyten FP, Lories RJ: Targets, models and challenges in osteoarthritis research. Dis Model Mech 2015;8:17-30.

3 Liang W, Ren K, Liu F, Cui W, Wang Q, Chen Z, Fan W: Periodic mechanical stress stimulates the FAK mitogenic signal in rat chondrocytes through ERK1/2 activity. Cell Physiol Biochem 2013;32:915-930.

4 Duval E, Baugé C, Andriamanalijaona R, Bénateau H, Leclercq S, Dutoit S, Poulain L, Galéra P, Boumédiene K: Molecular mechanism of hypoxia-induced chondrogenesis and its application in in vivo cartilage tissue engineering. Biomaterials 2012;33:6042-6051. 


\section{Cellular Physiology Cell Physiol Biochem 2015;37:1442-1453 \begin{tabular}{l|l} 
and Biochemistry Published online: October 23, 2015 & $\begin{array}{l}\text { C) 2015 S. Karger AG, Basel } \\
\text { www.karger.com/cpb }\end{array}$ \\
\hline
\end{tabular} \\ Zhang et al.: An Investigation Focused on miR-146a and Autophagy in Chondrocytes under Hypoxia}

5 Aro E, Khatri R, Gerard-O'Riley R, Mangiavini L, Myllyharju J, Schipani E: Hypoxia-inducible factor-1 (HIF1) but not HIF-2 is essential for hypoxic induction of collagen prolyl 4-hydroxylases in primary newborn mouse epiphyseal growth plate chondrocytes. J Biol Chem 2012;287:37134-37144.

6 Duval E, Leclercq S, Elissalde JM, Demoor M, Galéra P, Boumédiene K: Hypoxia-inducible factor $1 \alpha$ inhibits the fibroblast-like markers type I and type III collagen during hypoxia-induced chondrocyte redifferentiation: Hypoxia not only induces type II collagen and aggrecan, but it also inhibits type I and type III collagen in the hypoxia-inducible factor $1 \alpha$-dependent redifferentiation of chondrocytes. Arthritis Rheum 2009;60:3038-3048.

7 Sanz-Ramos P, Mora G, Vicente-Pascual M, Ochoa I, Alcaine C, Moreno R, Doblaré M, Izal-Azcárate Í: Response of sheep chondrocytes to changes in substrate stiffness from 2 to 20 Pa: effect of cell passaging. Connect Tissue Res 2013;54:159-166.

8 Provot S, Schipani E: Fetal Growth Plate: a developmental model of cellular adaptation to hypoxia. Ann N Y Acad Sci 2007;1117:26-39.

9 Chang Z, Huo L, Wu Y, Zhang P: HIF-1 $\alpha$ had Pivotal Effects on Downregulation of miR-210 Decreasing Viability and Inducing Apoptosis in Hypoxic Chondrocytes. The Scientific World J 2014;2014:876363.

10 Pfander D, Cramer T, Schipani E, Johnson RS: HIF-1 $\alpha$ controls extracellular matrix synthesis by epiphyseal chondrocytes. J Cell Sci 2003;116:1819-1826.

11 Bohensky J, Shapiro IM, Leshinsky S, Terkhorn SP, Adams CS, Srinivas V: HIF-1 regulation of chondrocyte apoptosis: induction of the autophagic pathway. Autophagy 2007;3:207-214.

12 Bohensky J, Leshinsky S, Srinivas V, Shapiro IM: Chondrocyte autophagy is stimulated by HIF-1 dependent AMPK activation and mTOR suppression. Pediatr Nephrol 2010;25:633-642.

13 Wu J, Niu J, Li X, Li Y, Wang X, Lin J, Zhang F: Hypoxia Induces Autophagy of Bone Marrow-Derived Mesenchymal Stem Cells via Activation of ERK1/2. Cell Physiol Biochem 2014;33:1467-1474.

14 Levine B, Kroemer G: Autophagy in the pathogenesis of disease. Cell 2008;132:27-42.

15 Guan X, Qian Y, Shen Y, Zhang L, Du Y, Dai H, Qian J, Yan Y: Autophagy Protects Renal Tubular Cells Against Ischemia/Reperfusion Injury in a Time-Dependent Manner. Cell Physiol Biochem 2015;36:285-298.

16 Almonte-Becerril M, Navarro-Garcia F, Gonzalez-Robles A, Vega-Lopez M, Lavalle C, Kouri J: Cell death of chondrocytes is a combination between apoptosis and autophagy during the pathogenesis of Osteoarthritis within an experimental model. Apoptosis 2010;15:631-638.

17 Caramés B, Kiosses WB, Akasaki Y, Brinson DC, Eap W, Koziol J, Lotz MK: Glucosamine activates autophagy in vitro and in vivo. Arthritis Rheum 2013;65:1843-1852.

18 Shapiro IM, Layfield R, Lotz M, Settembre C, Whitehouse C: Boning up on autophagy: the role of autophagy in skeletal biology. Autophagy 2014;10:7-19.

19 Rusten TE, Lindmo K, Juhász G, Sass M, Seglen PO, Brech A, Stenmark H: Programmed autophagy in the Drosophila fat body is induced by ecdysone through regulation of the PI3K pathway. Dev Cell 2004;7:179192.

20 Yue Z, Jin S, Yang C, Levine AJ, Heintz N: Beclin 1, an autophagy gene essential for early embryonic development, is a haploinsufficient tumor suppressor. Proc Natl Acad Sci USA 2003;100:15077-15082.

21 Füllgrabe J, Lynch-Day MA, Heldring N, Li W, Struijk RB, Ma Q Hermanson O, Rosenfeld MG, Klionsky DJ, Joseph B: The histone H4 lysine 16 acetyltransferase hMOF regulates the outcome of autophagy. Nature 2013;500:468-471.

22 Hu X, Sui X, Li L, Huang X, Rong R, Su X, Shi Q Mo L, Shu X, Kuang Y: Protocadherin 17 acts as a tumour suppressor inducing tumour cell apoptosis and autophagy, and is frequently methylated in gastric and colorectal cancers. J Pathol 2013;229:62-73.

23 Titone R, Morani F, Follo C, Vidoni C, Mezzanzanica D, Isidoro C: Epigenetic control of autophagy by microRNAs in ovarian cancer. Biomed Res Int 2014;2014:343542.

24 Brunet A, Sweeney LB, Sturgill JF, Chua KF, Greer PL, Lin Y, Tran H, Ross SE, Mostoslavsky R, Cohen HY: Stress-dependent regulation of FOXO transcription factors by the SIRT1 deacetylase. Science 2004;303:2011-2015.

25 Zhao Y, Yang J, Liao W, Liu X, Zhang H, Wang S, Wang D, Feng J, Yu L, Zhu W-G: Cytosolic Fox01 is essential for the induction of autophagy and tumour suppressor activity. Nat Cell Biol 2010;12:665-675.

26 Yi C, Ma M, Ran L, Zheng J, Tong J, Zhu J, Ma C, Sun Y, Zhang S, Feng W: Function and molecular mechanism of acetylation in autophagy regulation. Science 2012;336:474-477. 


\section{Cellular Physiology Cell Physiol Biochem 2015;37:1442-1453}

\begin{tabular}{l|l} 
Dant: 10.1159/000438513 & $\begin{array}{l}\text { 2 2015 } \mathrm{S} \text {. Karger AG, Basel } \\
\text { www.karger.com/cpb }\end{array}$ \\
\hline
\end{tabular}

Zhang et al.: An Investigation Focused on miR-146a and Autophagy in Chondrocytes under Hypoxia

27 Corradetti MN, Inoki K, Bardeesy N, DePinho RA, Guan K-L: Regulation of the TSC pathway by LKB1: evidence of a molecular link between tuberous sclerosis complex and Peutz-Jeghers syndrome. Genes Dev 2004;18:1533-1538.

28 Zhu H, Wu H, Liu X, Li B, Chen Y, Ren X, Liu C-G, Yang J-M: Regulation of autophagy by a beclin 1-targeted microRNA, miR-30a, in cancer cells. Autophagy 2009;5:816-823.

29 Ravikumar B, Imarisio S, Sarkar S, O'Kane CJ, Rubinsztein DC: Rab5 modulates aggregation and toxicity of mutant huntingtin through macroautophagy in cell and fly models of Huntington disease. J Cell Sci 2008;121:1649-1660.

30 Hu W, Chan CS, Wu R, Zhang C, Sun Y, Song JS, Tang LH, Levine AJ, Feng Z: Negative regulation of tumor suppressor p53 by microRNA miR-504. Mol Cell 2010;38:689-699.

31 Bartel DP: MicroRNAs: genomics, biogenesis, mechanism, and function. cell 2004;116:281-297.

32 Feng YY, Xu XQ, Ji CB, Shi CM, Guo XR, Fu JF: Aberrant hepatic microRNA expression in nonalcoholic fatty liver disease. Cell Physiol Biochem 2014;34:1983-1997.

33 Long W, Zhao C, Ji C, Ding H, Cui Y, Guo X, Shen R, Liu J: Characterization of serum microRNAs profile of PCOS and identification of novel non-invasive biomarkers. Cell Physiol Biochem 2014;33:1304-1315.

34 Bai R, Zhao A, Zhao Z, Liu W, Jian D: MicroRNA-195 induced apoptosis in hypoxic chondrocytes by targeting hypoxia-inducible factor 1 alpha. Eur Rev Med Pharmacol Sci 2015;19:545-551.

35 Seok J-K, Lee SH, Kim MJ, Lee Y-M: MicroRNA-382 induced by HIF-1 $\alpha$ is an angiogenic miR targeting the tumor suppressor phosphatase and tensin homolog. Nucleic Acids Res 2014;42:8062-8072.

36 Coimbra IB, Jimenez SA, Hawkins DF, Piera-Velazquez S, Stokes DG: Hypoxia inducible factor-1 alpha expression in human normal and osteoarthritic chondrocytes. Osteoarthritis Cartilage 2004;12:336-345.

37 Lotz MK, Caramés B: Autophagy and cartilage homeostasis mechanisms in joint health, aging and OA. Nat Rev Rheumatol 2011;7:579-587.

38 Shi Y, Li H, Zhang X, Fu Y, Huang Y, Lui PPY, Tang T, Dai K: Continuous cyclic mechanical tension inhibited Runx2 expression in mesenchymal stem cells through RhoA-ERK1/2 pathway. J Cell Physiol 2011;226:2159-2169.

39 Rippo MR, Olivieri F, Monsurrò V, Prattichizzo F, Albertini MC, Procopio AD: MitomiRs in human inflammaging: A hypothesis involving miR-181a, miR-34a and miR-146a. Exp Gerontol 2014;56:154-163.

40 Nakasa T, Miyaki S, Okubo A, Hashimoto M, Nishida K, Ochi M, Asahara H: Expression of microRNA-146 in rheumatoid arthritis synovial tissue. Arthritis Rheum 2008;58:1284-1292.

41 Pauley KM, Satoh M, Chan AL, Bubb MR, Reeves WH, Chan EK: Upregulated miR-146a expression in peripheral blood mononuclear cells from rheumatoid arthritis patients. Arthritis Res Ther 2008;10:R101.

42 Li J, Huang J, Dai L, Yu D, Chen Q Zhang X, Dai K: miR-146a, an IL-1beta responsive miRNA, induces vascular endothelial growth factor and chondrocyte apoptosis by targeting Smad4. Arthritis Res Ther 2012;14:R75.

43 Jin L, Zhao J, Jing W, Yan S, Wang X, Xiao C, Ma B: Role of miR-146a in human chondrocyte apoptosis in response to mechanical pressure injury in vitro. Int J Mol Med 2014;34:451-463.

44 Boldin M, Chang K: NF-kappaB-dependent induction of microRNA miR-146, an inhibitor targeted to signaling proteins of innate immune responses. Proc Natl Acad Sci USA 2006;103:12481-12486.

45 Nakasa T, Shibuya H, Nagata Y, Niimoto T, Ochi M: The inhibitory effect of microRNA-146a expression on bone destruction in collagen-induced arthritis. Arthritis Rheum 2011;63:1582-1590.

46 Wang J, Shih K, Wu Y, Wang A, Yang C: Histone deacetylase inhibitors increase microRNA-146a expression and enhance negative regulation of interleukin-1 $\beta$ signaling in osteoarthritis fibroblast-like synoviocytes. Osteoarthritis Cartilage 2013;21:1987-1996.

47 Li X, Kroin JS, Kc R, Gibson G, Chen D, Corbett GT, Pahan K, Fayyaz S, Kim JS, van Wijnen AJ: Altered spinal microRNA-146a and the microRNA-183 cluster contribute to osteoarthritic pain in knee joints. J Bone Miner Res 2013;28:2512-2522.

48 Gu S-X, Li X, Hamilton JL, Chee A, Kc R, Chen D, An HS, Kim J-S, Ma Y-Z, van Wijnen AJ: MicroRNA-146a reduces IL-1 dependent inflammatory responses in the intervertebral disc. Gene 2015;555:80-87.

49 Jones S, Watkins G, Le Good N, Roberts S, Murphy C, Brockbank S, Needham M, Read S, Newham P: The identification of differentially expressed microRNA in osteoarthritic tissue that modulate the production of TNF- $\alpha$ and MMP13. Osteoarthritis Cartilage 2009;17:464-472. 